\title{
Yatırım, Kaldıraç ve Büyüme Fırsatları: BIST İmalat Sektörü Firmalarında Bir Uygulama
}

Burcu DINÇERGÖK*

\section{ÖZET}

Bu çalışmada Türkiye'de yatırımlar, büyüme firsatları ve kaldıraç arasındaki ilişki araştırllmaktadır. 2005- 2013 yılları arasında Borsa Ístanbul'a kayıtlı belirli sayıda imalat sektörü firması kullanılarak panel veri analizi gerçekleştirilmiştir. Analiz sonuçlarına göre nakit akımı ve satışlar yatırımları pozitif yönde etkilemektedir. Kaldıraç ve yatırımlar arasındaki ilişki beklendiği üzere negatiftir. Söz konusu negatif ilişki düşük büyüme firsatlarına sahip firmalarda yüksek büyüme firsatlarına sahip firmalardan daha güçlüdür. Bu sonuç, kaldıracın yönetimi disipline edip, aşırı yatırımları azalttığ yönündeki temsilcilik teorisine destek vermektedir. Düşük düzeyde uzun vadeli borcu olan firmalarda ise büyüme firsatlarının artması yatırımları olumsuz yönde etkilemekte iken, düşük düzeyde kısa vadeli borca sahip firmalarda etki pozitiftir. Yüksek düzeyde kaldıraca sahip firmalarda elde edilen ilişki istatistiki açıdan anlamlı değildir.

Anahtar Kelimeler: Yatırım, kaldıraç, büyüme firsatları, Türkiye

JEL Sınıflaması: G31, G32

\begin{abstract}
Investments, Leverage and Growth Opportunities: An Application on BIST Manufacturing Sector Firms

\section{ABSTRACT}

This study investigates the relationship between investments, growth opportunities and leverage in Turkey. A sample of manufacturing firms that are quoted to Istanbul Stock Exchange between the years of 2005 -2013 is analyzed using panel data analysis. According to the results of the analysis cash flow and sales positively affect investments. The relationship between leverage and investment is found to be negative as expected. The negative relationship is stronger for firms that have low growth opportunities than the firms that has high growth opportunities. This result support the agency theory stating that the leverage diciplines management and reduces overinvestment. For the firms that have low levels of long term debt, the effect of growth opportunities on investment is negative whereas for low levels of short term debt the effect is positive. The results are insignificant for the firms that have high levels of leverage.
\end{abstract}

Keywords: Investment, leverage, growth opportunities, Turkey.

Jel Classification: G31,G32

\footnotetext{
* Yrd. Doç. Dr. Burcu Dinçergök, Atılım Üniversitesi, İşletme Fakültesi, İşletme Bölümü, burcu.dincergok@atilim.edu.tr
} 


\section{GÍRIŞ}

Yatırımlar ve finansman yapısı kararları arasındaki ilişki finans literatüründe uzun yıllardan beri tartışılan bir konudur. Modigliani ve Miller (1958), mükemmel piyasalar varsayımına dayanan modellerinde, yatırım kararlarının ve ağırlıklı ortalama sermaye maliyetinin finansman yapısı kararlarından bağımsız olduğunu ifade etmiş olsa da mükemmel olmayan piyasaların hüküm sürdüğü günümüz dünyasında yapılan araştırmalar yatırım kararlarının finansman kararlarından bağımsız olmadığını ortaya koymaktadır.

Yönetici ve hissedar çatışmasına neden olan aşırı yatırım problemi Temsilcilik teorisinde ortaya konulmuştur. Jensen (1986)'a göre yönetim, serbest nakit akımlarını1, kendi çıkarları nedeniyle, ortaklara dağıtmak istemez.Bunun yerine bu nakit akımlarını sermaye maliyetinin altında getiri sağlayan yatırımlara aktarmayı tercih eder ki bu durum aşırı yatırım problemi olarak adlandırılmaktadır. Eldeki varlıkları fazla olan firmalar daha fazla nakit akımı üretirler ve bu firmalar aşırı yatırım problemine daha fazla açıktır (Harvey, 2004: 5). Ancak sermaye piyasalarının bu gibi bir eğilimi sezinlediği bir durumda ya da firmanın devralınma ihtimali söz konusu olduğunda, böyle bir strateji yöneticilere pahalıya mal olabilir. Borç, firmay1 belirli zamanlarda belirli tutarlarda ödeme yapmaya zorladığı için aşırı yatırım problemini çözmede bir araç olarak kullanılabilir ve yönetim tarafından da tercih edilir.Stulz (1990) da borcun serbest nakit akımlarını azaltarak aşırı yatırım problemini azaltacağı yönünde Jensen (1986) ile hemfikirdir. Bu teoriler aslında özellikle düşük büyüme firsatlarına sahip olan firmalarda kaldıraç ve yatırımlar arasında negatif ilişkinin beklenebileceği sonucu ima etmektedirler (Aivazian,vd.,2005: 279).

Temsilcilik teorisine göre borcun temsilcilik maliyetlerinden bir tanesi de eksik yatırım problemidir. Myers (1977) yüksek borç düzeylerinin, hissedar- kreditör arasındaki çıkar çatışmaları nedeniyle, pozitif net bugünkü değere sahip projelerin reddedilmesine neden olduğunu ifade etmiştir. Burada, hissedarlar ve kreditörler arasında çatışmaya neden olan şey, proje getirisinden büyük ölçüde borç verenlerin faydalanması ancak hissedarların projenin maliyetine katlanacak olmasıdır. Buna ek olarak Stulz (1990) da, yüksek düzeyde borçlanmanın değer arttırıcı projelere yatırım yapmayı engelleyeceğini ifade etmiştir. Bu teori, yüksek kaldıraç oranlarına sahip olan firmaların, aşırı borç yükü nedeniyle iyi büyüme fırsatlarını kaçııı, yatırımlarının azalacağını ifade etmektedir. Buradan hareketle, kaldıraç oranları düşük olan firmaların iyi büyüme firsatlarından faydalanıp yatırımlarının artacağı yorumu yapılabilir.

Yukarıda ifade edildiği üzere, büyüme firsatlarının düşük ya da yüksek olması kaldıraç ve yatırımlar arasında beklenen negatif ilişkiyi etkilememektedir. Ancak, düşük büyüme fırsatlarına sahip firmalarda bulunan söz konusu negatif ilişki hissedar ve yönetim arasındaki çıkar çatışmalarını önleyip, aşırı yatırımı azaltırken, yüksek büyüme firsatlarına sahip firmalarda bulunan söz konusu negatif ilişki hissedar ve borç veren arasındaki çıkar

\footnotetext{
${ }^{1}$ Serbest nakit akımı, sermaye maliyeti ile iskonto edilen pozitif net bugünkü değere sahip projeler finanse edildikten sonra arda kalan nakit akımı olarak tanımlanmıştır (Jensen, 1986).
} 
çatışmalarına dayanan eksik yatırım problemini teşvik etmektedir. Dolayısıyla, kaldıraç ve yatırımlar arasında beklenen negatif ilişkinin yüksek büyüme ve düşük büyüme fırsatına sahip firmalar için ifade edeceği anlam farklılaşmaktadır.

Bu çalışmada üç önemli sorunun yanıtı ortaya konulacaktır. Öncelikle Türkiye'de kaldıraç ve yatırımlar arasındaki ilişki temsilcilik teorilerinin beklediği gibi negatif yönlü bir ilişki midir? İkincisi düşük büyüme firsatlarına sahip olan firmalarda mı, yoksa yüksek büyüme fırsatlarına sahip olan firmalarda mı ilişki daha güçlüdür? Üçüncü soru ise kaldıraç oranı yüksek olan ya da düşük olan firmalarda büyüme firsatlarının artması kaldıraç ve yatırım ilişkisini nasıl etkiler? Bu sorulara verilecek yanıt kaldıracın, yüksek büyüme firsatlarına sahip firmalarda düşük büyüme firsatlarına sahip firmalara göre göreceli önemini ortaya koyarken, belirli düzeyde kaldıraca sahip firmalar için büyüme firsatlarının ifade ettiği anlamın netleşmesine katkıda bulunacaktır.

\section{LITERATÜR TARAMASI}

McConnell ve Servaes (1995), 1976, 1986 ve 1988 yıllarında firmaları düşük büyüme ve yüksek büyüme fırsatlarına sahip olan firmalar olarak iki gruba ayırdıkları çalışmada, yüksek büyüme firsatlarına sahip firmalarda firma değerinin borç ile ters yönde ilişkili olduğunu ve düşük büyüme firsatlarına sahip firmalarda ise firma değerinin borçla pozitif yönde ilişkili olduğu sonuçlarını ortaya koymuşlardır. Bulunan sonuç kaldıracın eksik yatırımı teşvik edip firma değerini azaltması ve yine kaldıracın aşırı yatırımı azaltıp firma değerini arttırması hipotezleriyle uyumludur.

Lang, vd. (1996), 1970-1989 yılları arasında A.B.D.'deki büyük sanayi firmaları üzerinde yapmış oldukları araştırmada düşük büyüme firsatlarına sahip firmalar için kaldıraç ve yatırımlar arasında negatif ilişki tespit ederken aynı ilişkinin yüksek büyüme fırsatlarına sahip firmalar için söz konusu olmadığını dile getirmişlerdir. Bu sonuçlar aslında kaldıracın aşırı yatırım problemini engellediği hipoteziyle uyumludur.

Aivazian, vd. (2005), Kanada'da halka açık firmalar üzerinde 1982-1999 yılları arasındaki verileri kullanarak yapmış oldukları panel veri analizi sonucunda, kaldıraç ve yatırımlar arasında negatif ilişki olduğunu ve bu ilişkinin düşük büyüme firsatlarına sahip olan firmalarda, yüksek büyüme firsatlarına sahip olan firmalardan daha güçlü olduğunu ifade etmişlerdir.

Ahn, vd. (2006), çeşitleme yapmış olan firmalarda 1982 -1997 döneminde kaldıracın yatırımlar üzerindeki negatif etkisinin, yüksek Tobin Q oranına sahip bölümlerde düşük Tobin Q oranına sahip bölümlere göre daha büyük ve güçlü olduğunu ortaya koymuşlardır. Ayrıca düşük büyüme firsatına sahip firmalarda kaldıraç ve firma değeri arasındaki pozitif ilişkinin çeşitlenmiş firmalarda diğer firmalardan daha zayıf olduğunu ifade etmişlerdir.

Karacaer, vd. (2009) Türkiye’de 2000-2006 döneminde regresyon ve korelasyon analizi kullanarak yapmış oldukları çalışmada, kaldıracın firma yatırımları üzerinde negatif etkiye sahip olduğunu, düşük büyüme firsatlarına sahip firmalarda ilişkinin istatistiksel olarak anlamlı olduğunu ifade etmişlerdir. 
Umutlu (2010) Türkiye’de 1993-2002 döneminde tek yönlü hata bileşen modeline göre sadece düşük büyüme firsatlarına sahip olan firmalarda kaldıracın yatırımlar üzerinde etkili olduğunu, iki yönlü hata bileşen modeline göre ise bu ilişkinin kaybolduğunu ifade etmişti.

Bao (2010), Çin'deki iki sermaye piyasasına kayıtlı firmalar üzerinde 1992-2009 yılları verilerini kullanarak yaptığı OLS analizleri sonucunda, tüm firmalar baz alındığında finansal kaldıraç ve yatırım ilişkisinin istatistiki olarak anlamlı ve negatif olduğunu ortaya koyarken, sektörler arasında ayrıştırma yapıldığında, imalat, ticaret ve finans sektörü için söz konusu ilişkinin istatistiki olarak anlamlı olmadığını ifade etmiştir. Çalışmada ayrıca devlete ait firmalarda kaldıracın yatırımlar üzerindeki ters etkisinin özel sektöre ait firmalarınki kadar güçlü olmadığını, büyüme fırsatlarının yatırımlar üzerindeki pozitif etkisinin sadece marjinal q oranı 1'den küçük firmalar için geçerli olduğu, kaldıraç ve yatırımlar arasındaki negatif ilişkinin marjinal q oranı 1'den büyük olan firmalar için sözkonusu olduğu ve yüksek kaldıraca sahip firmaların önlerinde karlı büyüme firsatları olsa dahi yatırım yapmaktan kaçındıkları sonuçlarına ulaşılmıştır.

Ma'in ve Ismail (2010), Malezya'da 300 firmayı panel veri analizi yöntemi ile 2000-2007 döneminde analiz etmiş oldukları çalışmada, toplam borç oranı ve sabit yatırımlar arasında negatif, toplam banka kredisi oranı ve sabit yatırımlar arasında pozitif ilişki olduğunu ancak anlamlılık düzeyinin istatistiki açıdan düşük olduğunu ifade etmişler, bunun dışında nakit akımları, Tobin Q oranı ve yatırımlar arasında pozitif ilişki saptamışlardır. Çalışmada banka kredilerinin aşırı yatırım problemini engellediği sonucuna ulaşılmıştır.

Franklin ve Muthusamy (2011), Hindistan'da sermaye piyasasına kayıtlı 25 ilaç firması üzerinde panel veri analizini kullanarak yapmış oldukları araştırmada, kaldıraç ve yatırımlar arasında pozitif ilişki olduğunu ve bu pozitif ilişsinin sadece küçük firmalarda istatistiki olarak anlamlı olduğunu ifade etmişlerdir. Çalışmada yatırımların nakit akımları ve dağıtılmamış karlardan önemli ölçüde etkilendiği ortaya konulmuştur.

Wu (2013) 13 Avrupa ülkesindeki 523 firmayı havuz regresyon yöntemine göre analiz ettiği çalışmasında, sermaye harcamaları ve kaldıraç arasında anlamlı bir ilişki bulamazken, düşük büyüme firsatlarına sahip firmalarda borcun yönetimce yapılan aşırı harcamaları azalttığına dair kanıt sunmuştur.

\section{VERİ VE YÖNTEM}

Çalışmada, Datastream veri tabanında yer alan ve Borsa İstanbul'da kayıtlı olan imalat sektöründeki firmaların ilgili verileri kullanılmıştır. Çalışmada kullanılan değişkenler, DataStream veri tabanında yer alan firma hesapları verileri (CompanyAccounts Data), bilanço ve gelir tablosu verilerinden faydalanarak hesaplanmıştır. Ancak DataStream veri tabanında yer alan toplam varlıklar hesap kalemi ertelenmiş vergi varlıklarını kapsamadığı için, Borsa İstanbul'da yer alan bilançolardan hareketle bu veri düzeltilmiştir. Çalışma, 2005-2013 
yıllarını kapsamaktadır. ${ }^{2}$

İlgili dönemde verilerine ulaşılabilen toplam 135 firmaya ait 1077 gözlemle dengesiz panel veri kullanılarak panel veri analizi gerçekleştirilmiştir.

Çalışmada ilk olarak, Lang vd. (1996) ve Aivazian, vd. (2005) çalışması izlenerek aşağıdaki modeller oluşturulmuştur.

$$
\begin{aligned}
& Y_{i, t} / K_{i, t-1=} \alpha+\lambda_{t}+\beta\left(N A_{i, t} / T V_{i, t-1}\right)+\delta Q_{i}{ }_{t-1}+\eta K A L_{i, t-1}+\vartheta\left(S A T_{i, t-1} / K_{i, t-1}\right)+\mu_{i}+\varepsilon_{i, t}
\end{aligned}
$$

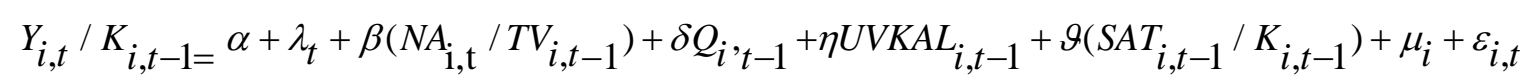

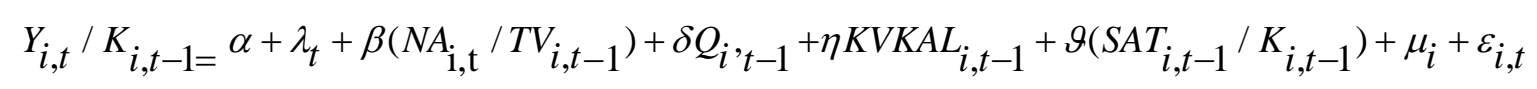

Model (1), (2) ve (3)'de kullanılan bağımlı değişken yatırımların maddi duran varlıklara bölünmesi ile elde edilen $Y_{i, t} / K_{i, t-1}$ değişkenidir. $Y_{i, t}$ ile ifade edilen yatırımlar t dönemindeki sermaye harcamalarının bir önceki dönemdeki $K_{i, t-1}$ ile ifade edilen net maddi duran varlıklara oranlanması ile elde edilmiştir. Çalışmada kullanılan kontrol değişkenleri ise nakit akımları, Tobin $\mathrm{Q}$ oranı ve satışlara ilişkin değişkenlerdir. $N A_{\mathrm{i}, \mathrm{t}}$ ile ifade edilen nakit akımları vergi sonrası kara amortismanların eklenmesi suretiyle hesaplanmıştır ve bir önceki dönemin toplam varlıklarına bölünmesi suretiyle $N A_{i, t} / T V_{i, t-1}$ değişkeni elde edilmiştir. $S A T_{i, t-1} / K_{i, t-1}$ ifade edilen değişken ise bir önceki dönemdeki satışların yine aynı dönemdeki net maddi duran varlıklara bölünmesi ile elde edilmiştir. Tüm modellerde alan $Q_{i},_{t-1}$ değişken bir önceki dönemdeki Tobin Q oranının göstergesidir. Finans literatüründe performans göstergesi ve büyüme firsatlarının göstergesi olarak kullanılan Tobin Q oranı, borçların defter değerini ve özkaynakların piyasa değeri toplamının varlıkların cari yerine koyma değerine oranı şeklinde ifade edilmektedir. ${ }^{3}$ Ancak, varlıkların cari yerine koyma değerinin hesaplamasının güç olması nedeniyle söz konusu oran Chung ve Pruitt (1994) tarafından varlıkların defter değeri kullanılarak basit hali ile hesaplanmıştır. Bu çalışmada da Tobin Q oranı aşağıdaki formüle göre hesaplanmıştır.

\footnotetext{
${ }^{2}$ Borsa İstanbul'a kayıtlı olan firmalar 2005 yılında finansal tablolarını uluslararası finansal raporlama standartları ile uyumlu şekilde hazırlamaya başlamışlardır. Mali tabloların muhasebe uygulamaları açısından uyumluluk arz etmesi hedeflenerek analiz dönemi olarak söz konusu dönem seçilmiştir.

${ }^{3}$ Tobin q oranının paydasında firma varlıklarının defter değeri bulunmaktadır ve bu değer eldeki varlıkların değerini ifade etmektedir. Dolayısıyla Tobin q oranı ve eldeki varlıkların ters yönde ilişkili olması beklenmektedir (Alonso, 2005: 396). Eldeki varlıkları fazla olan firmaların nakit akımları da fazla olacağı beklenmektedir (Harvey, 2004: 5).
} 
Tobin Q= ( Kısa Vadeli Borçlar + Uzun Vadeli Borçlar+ Özsermaye Piyasa Değeri)/Toplam Varlıklar

Model (1)'deki $K A L_{i, t-1}$ kaldıraç değişkeninin göstergesidir, kaldıraç değişkeni toplam yabancı kaynakların toplam varlıklara oranlanması ile hesaplanmıştır. Model (2)'deki $U V K A L_{i, t-1}$ uzun vadeli yabancı kaynakların toplam varlıklara bölünmesi ile elde edilen uzun vadeli borçlanmayı ifade eden kaldıraç değişkenidir. Model (3)'deki $K V K A L_{i, t-1}$ ise kısa vadeli borçlanmayı ifade eden kaldıraç değişkenidir. Söz konusu değişkenler gecikmeli değerleri ile hesaplanmış ve kullanılmıştır.

Her üç modeldeki, $\alpha$ sabit terimi ifade ederken, $\lambda_{t}$ ise 2005, 2006, 2007, 2008, 2009, 2010, 2011, 2012 ve 2013 yıllarının her biri için oluşturulmuş bir zaman kukla değişkenidir. $\lambda_{t}, \mathrm{t}$ yılındaki gözlemler için 1 değerini alırken diğer yıllar için 0 değerini almaktadır. Modellerdeki diğer değişkenler olan, $\mu_{i}$ bireye özgü hata terimini, $\varepsilon_{i, t}$ ise hem yatay kesit hem de bireye özgü hata terimini göstermektedir.

Teoriyi uygun olarak kaldıraç değişkeni ve yatırımlar arasında negatif ilişki beklenirken, nakit akımları, satışlar, Tobin Q oranı ve yatırımlar arasında beklenen ilişki pozitif yönlüdür.

Çalışmada kullanılan veri seti hem zaman serisi, hem de yatay kesit boyutu olan verilerdir. Panel veri analizi yöntemi diğer ekonometrik yöntemlerle kıyaslandığında, firmalar arasındaki heterojenliği dikkate alması, daha fazla serbestlik derecesi sunması, daha fazla değişkeni kapsamına alabilmesi gibi nedenler ve bunların yanında çoklu bağıntı probleminin bu yöntemde sıklıkla yaşanmaması nedenleriyle bu çalışmada tercih edilmiştir (Hsiao, 1986: 2; Baltagi, 2005: 3- 5 ).

Panel veri analizi yöntemi, bireysel etkilerin bağımsız değişkenlerle aralarında korelasyon olup olmadığı varsayımlarına göre sabit etkiler modeli ve tesadüfi etkiler modeli şeklinde uygulanabilmektedir. Sabit etkiler modelinde bireylere ait olan gözlemlenemeyen etkilerin bağımsız değişkenlerle aralarında korelasyon olduğu varsayılıp uygulamada buna izin verilirken, tesadüfi etkiler modelinde bireye özgü hata terimleri ve bağımsız değişkenler arasında korelasyonun olmadığı varsayılmaktadır (Hsiao, 2005: 10). Bu nedenle, eğer bireysel etkilerle bağımsız değişkenler arasında korelasyon olduğu düşünülüyorsa, sabit etkiler modelinin, eğer bireysel etkiler ve bağımsız değişkenler arasında korelasyonun olmadığı düşünülüyorsa tesadüfi etkiler modelinin kullanılması uygundur (Greene, 2003: 650). 
Çalışmada hangi modelin kullanılacağına karar verilmesi için Hausman (1978) testi uygulanmıştır. Hausman testi sabit etkiler modelinin ve tesadüfi etkiler modelinin parametre tahmincileri arasındaki farkın istatistiki olarak anlamlı olup olmadığını ölçmektedir. Eğer fark istatistiki olarak anlamlı ise sabit etkiler modeli, anlamlı değil ise tesadüfi etkiler modeli kullanilır (Dougherty, 2007: 420- 421).

Çalışmada yanıtı aranan ikinci sorunun, yani büyüme fırsatları iyi olan firmalarda mı yoksa kötü büyüme fırsatlarına sahip olan firmalar da mı kaldıraç yatırım ilişkisi daha güçlüdür sorusunun yanıtı için Tobin Q'su 1'den büyük firmalar ve TobinQ'su 1'den küçük firmalar birbirinden kukla değişken oluşturularak ayrıştırılmıştır. $D_{i, t-1}$ kukla değişkeni Tobin Q>1 olduğunda 1 değerini, diğer durumlarda 0 değerini almaktadır. $D_{i, t-1} * K A L_{i, t-1}$ değişkeni ise söz konusu kukla değişkenle kaldıraç oranının çarpımından oluşan bir etkileşim terimidir. Diğer terimler 1. modeldeki ile aynıdır. Model (4)'de toplam yabancı kaynaklar, Model (5)'de uzun vadeli yabancı kaynaklar, Model (6)'da ise kısa vadeli yabancı kaynaklar kullanılarak hesaplanan kaldıraç oranları ve etkileşim terimleri kullanılmıştır.

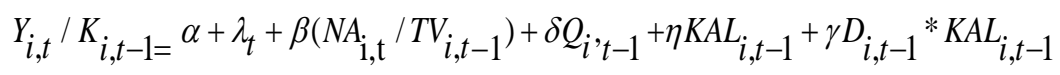

$$
\begin{aligned}
& +\vartheta\left(S_{i, t-1} / K_{i, t-1}\right)+\mu_{i}+\varepsilon_{i, t}(4) \\
& Y_{i, t} / K_{i, t-1=} \alpha+\lambda_{t}+\beta\left(N A_{1, t} / T V_{i, t-1}\right)+\delta Q_{i, t-1}+\eta U V K A L_{i, t-1}+\gamma D_{i, t-1} * U V K A L_{i, t-1} \\
& +\vartheta\left(S A T_{i, t-1} / K_{i, t-1}\right)+\mu_{i}+\varepsilon_{i, t}
\end{aligned}
$$

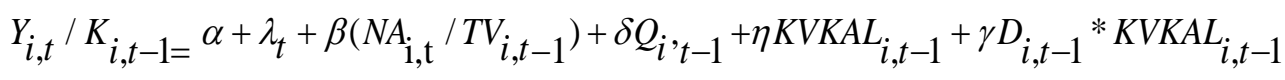

$$
\begin{aligned}
& +\vartheta\left(S A T_{i, t-1} / K_{i, t-1}\right)+\mu_{i}+\varepsilon_{i, t} \quad \text { (6) }
\end{aligned}
$$

Kaldıraç oranı yüksek ve düşük olan firmalarda büyüme fırsatlarının artması yatırımları nasıl etkiler sorusunun yanıtı için ise Bao (2010)'a benzer şekilde kukla değişkenler oluşturulup, Model (7), (8) ve (9) analiz edilmiştir. Modelde iki adet kukla değişken bulunmaktadır. $D_{\text {kdüsü }, t-1}$ kukla değişkeni kaldıraç oranı 1. katrile eşit ya da küçük ise 1 değerini alırken, $D_{\text {kyüksek,t-1 }}$ kukla değişskeni kaldıraç oranı 3. kartile eşit ya da yüksek ise 1 değerini almaktadır. $D_{\text {kdüsüik,t-1 }} * Q_{i, t-1}$ değişkeni ise $D_{\text {kdüsüuk }, t-1}$ kukla değişkeni ve bir önceki dönemin Tobin Q oranı çarpımından oluşan bir etkileşim terimidir. Aynı şekilde 
$D_{k y u ̈ k s e k, t-1} * Q_{i, t-1}$ değiş̧keni $D_{k y u ̈ k s e k, t-1}$ ve bir önceki dönemin Tobin Q oranı çarpımından oluşan bir etkileşim terimidir. Model (8) ve (9)'da aynı uygulama, sırasıyla uzun vadeli ve kısa vadeli borçlanma oranları için yapılmıştır.

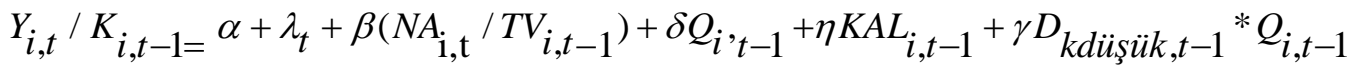

$$
\begin{aligned}
& +\phi D_{\text {kyüksek,t-1 }} * Q_{i, t-1}+\vartheta\left(S A \mathrm{~T}_{\mathrm{i}, \mathrm{t}-1} / K_{i, t-1}\right)+\mu_{i}+\varepsilon_{i, t} \\
& Y_{i, t} / K_{i, t-1=} \alpha+\lambda_{t}+\beta\left(N A_{i, \mathrm{t}} / T V_{i, t-1}\right)+\delta Q_{i,{ }_{t-1}}+\eta U V K A L_{i, t-1}+\gamma D_{u v k d u ̈ s u ̈ k, t-1} * Q_{i, t-1} \\
& +\phi D_{u v k k y u ̈ k s e k, t-1} * Q_{i, t-1}+\vartheta\left(S A T_{i, t-1} / K_{i, t-1}\right)+\mu_{i}+\varepsilon_{i, t} \\
& Y_{i, t} / K_{i, t-1=} \alpha+\lambda_{t}+\beta\left(N A_{i, \mathrm{t}} / T V_{i, t-1}\right)+\delta Q_{i},_{t-1}+\eta K V K A L_{i, t-1}+\gamma D_{k v k d u ̈ s u ̈ k, t-1} * Q_{i, t-1} \\
& +\phi D_{k v k k y u ̈ k s e k, t-1} * Q_{i, t-1}+\vartheta\left(S A T_{i, t-1} / K_{i, t-1}\right)+\mu_{i}+\varepsilon_{i, t}
\end{aligned}
$$

\section{ANALIZ SONUÇLARI}

Çalışmada kullanılan değişkenlere ilişkin özet istatistikler Tablo 1'de yer almaktadır. Tablo 1'de görüldüğü üzere yatırımların maddi duran varlıklara olan oranının ortalaması $0.1698^{\prime}$ tir. Analiz döneminde yatırım oranı düşük değerdedir. Yatırımların standart sapması ise 0. 2362'dir. Tobin Q değeri ortalaması 1.3726 ile 1 değerinin üzerindedir ki bu durum analiz döneminde piyasada büyüme fırsatlarına ilişkin olarak olumlu bir beklenti olduğunu göstermektedir. Toplam yabancı kaynakların toplam varlıklara oranı ortalama olarak 0. 4545, uzun vadeli borçların toplam varlıklara olan oranının ortalama olarak 0.1259'dir. Kısa vadeli yabancı kaynak ortalaması ise 0.3286 'dır. Bu durum analiz edilen firmaların büyük ölçüde kısa vadeli yabancı kaynak kullandıklarına işaret etmektedir.

Tablo 1: Özet İstatistikler

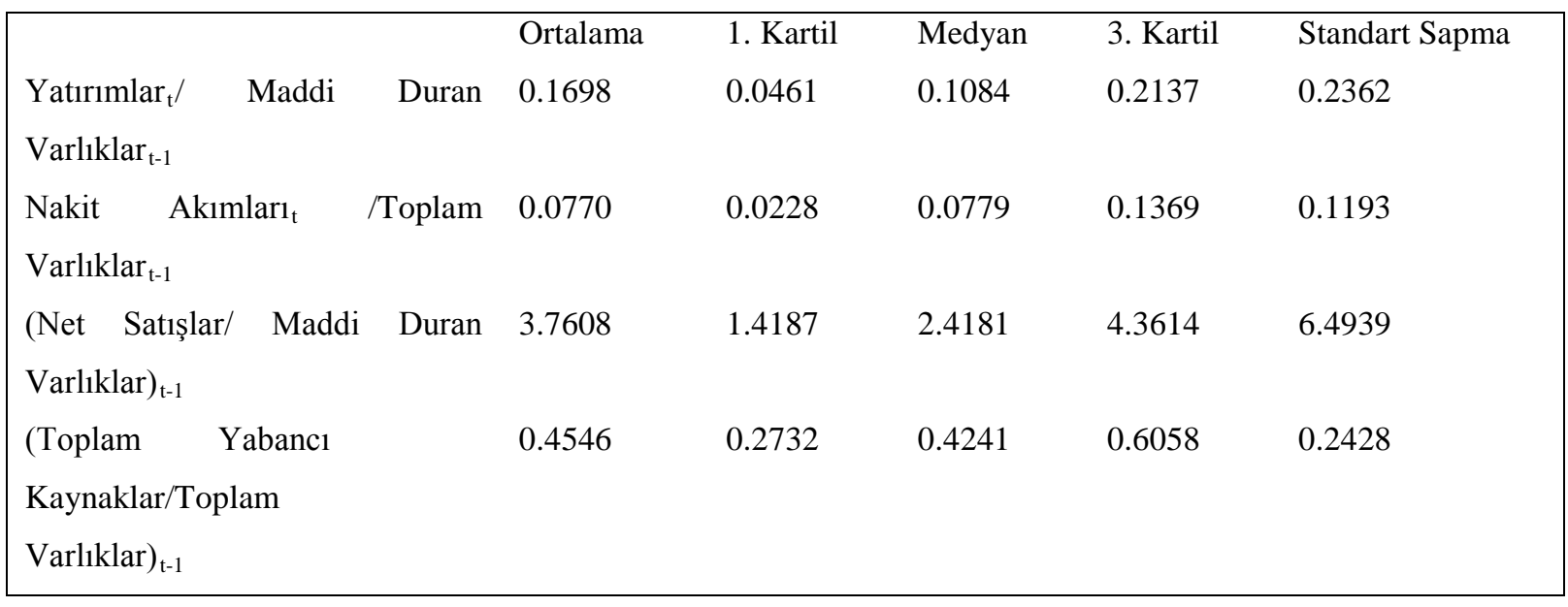




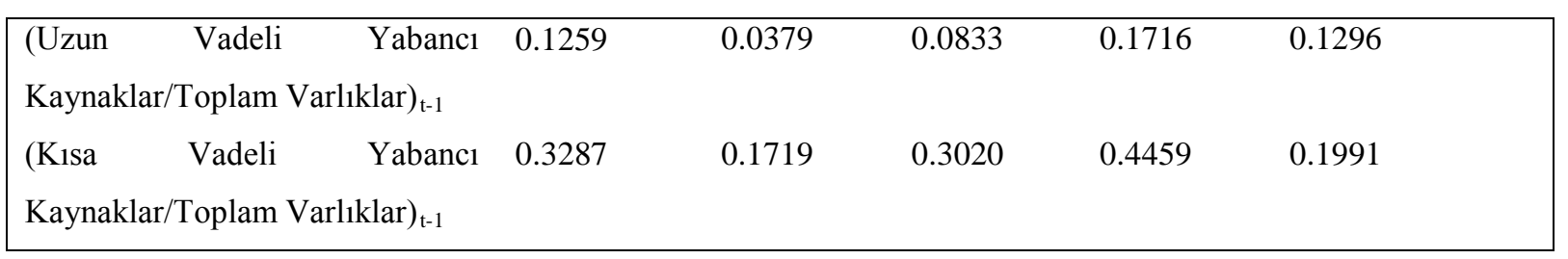

Panel veri analizi yöntemlerinden sabit etkiler ya da tesadüfi etkiler modellerinden hangisinin kullanılacağına karar verilmesi için Hausman testi yapılmıştır. Hausman test sonuçları Tablo 2'de verilmiştir.

Tablo 2: Hausman Test Sonuçları

\begin{tabular}{|l|l|l|l|l|l|l|l|l|l|}
\hline & Model1 & Model2 & Model3 & Model4 & Model5 & Model6 & Model7 & Model8 & Model9 \\
\hline $\begin{array}{l}\text { Hausman } \\
\text { sonucu }\end{array}$ & 76.24 & 56.37 & 69.51 & 75.97 & 53.16 & 70.75 & 77.73 & 56.91 & 72.14 \\
\hline P-Değeri & $0.000^{* * *}$ & $0.000^{* * *}$ & $0.000^{* * *}$ & $0.000^{* * *}$ & $0.000^{* * *}$ & $0.000^{* * *}$ & $0.000^{* * *}$ & $0.000^{* * *}$ & $0.000^{* * *}$ \\
\hline
\end{tabular}

Hausman test sonuçlarına göre tüm modellerde sabit etkiler ve tesadüfi etkiler modellerinin parametre tahmincilerine ilişkin fark istatistiki olarak anlamlıdır. Bu nedenle çalışmada sabit etkiler modeli sonuçlarına yer verilecektir.

Tablo 3, Model (1) , (2) ve (3)'ün panel veri analizi sonuçlarını göstermektedir. Elde edilen sonuçlar toplam borç oranları, kısa vadeli borç oranları ve yatırımlar arasında istatistiki açıdan anlamlı negatif ilişki olduğunu göstermektedir. Sonuçlar temsilcilik teorilerinin beklentileri ile uyumludur. Uzun vadeli borç oranları ve yatırım ilişkisi ise negatif olmasına rağmen istatistiki olarak anlamlı değildir. Her üç modelde de nakit akımları ve satışlar yatırımları pozitif yönde etkilemektedir ve sonuçlar istatistiki olarak önemlidir. Tobin Q oranı ve yatırımlar arasında pozitif ilişki bulunmuş olsa da, söz konusu ilişki istatistiki açıdan anlamlı değildir.

Yüksek büyüme firsatı ve düşük büyüme fırsatlarına sahip firmalarda kaldıraç oranları ve yatırım ilişkisinin analizi için oluşturulan Model (4), (5) ve (6)’ya ilişkin panel veri analizi sonuçları ise Tablo 4'te gösterilmiştir.

Model (4)'ten elde edilen sonuçlar kaldıraç oranları ve yatırımlar arasında istatistiki açıdan anlamlı negatif ilişkiyi ortaya koyarken, satışlar ve yatırımlar arasında pozitif, nakit akımları ve yatırımlar arasında da pozitif ilişki tespit edilmiştir. Veri ve Yöntem bölümünde açıklandığı üzere $D_{i, t-1} * K A L_{i, t-1}$ değişkeni $D_{i, t-1} \quad$ kukla değişkeni ve kaldıraç oranının çarpımından oluşan bir etkileşim terimidir. Buradaki kukla değişken olan $D_{i, t-1}$, Tobin $\mathrm{Q}$ değeri 1 'in üzerinde olduğunda 1 değerini aksi durumda 0 değerini almaktadır. Model (4)' ten elde edilen sonuçlara göre Tobin Q değeri 1'den küçük firmalar için kaldıraç değişkeni katsayıs1 -0.329 iken, Tobin Q değeri 1'den büyük firmalar için bu katsayı -0. 248 (-0.329+ 
0.081) değerini alacaktır. Ayrıca kaldıraç değişkeni katsayısı \%1 düzeyinde anlamlı iken, etkileşim terimi katsayısı \%5 düzeyinde anlamlıdır. Dolayısıyla analiz sonucunda, kaldıraç ve yatırımlar arasındaki negatif ilişkinin Tobin Q değeri 1'den düşük, bir diğer değiş̧le büyüme firsatları daha az olan firmalar için daha güçlü bir negatif ilişki olduğu sonucu ortaya konulmuştur. Model (5)'te yani uzun vadeli yabancı kaynaklar kullanılarak hesaplanan kaldıraç oranına dayanan modelde ise uzun vadeli borçlanma ve yatırımlar arasında negatif ancak istatistiki açıdan anlamlı olmayan ilişki olduğu, satışlar, nakit akımları ve yatırımlar arasında ise pozitif ve anlamlı ilişki olduğu sonucuna varılmış, ancak etkileşim terimi istatistiki yönden anlamlı sonuç vermemiştir. Model (6)'nın sonuçları da Model (4) ile uyumludur.

Tablo 3: Panel Veri Analizi Sonuçları- Yatırım Modelleri Sonuçları

\begin{tabular}{|c|c|c|c|c|c|c|}
\hline \multicolumn{7}{|c|}{ 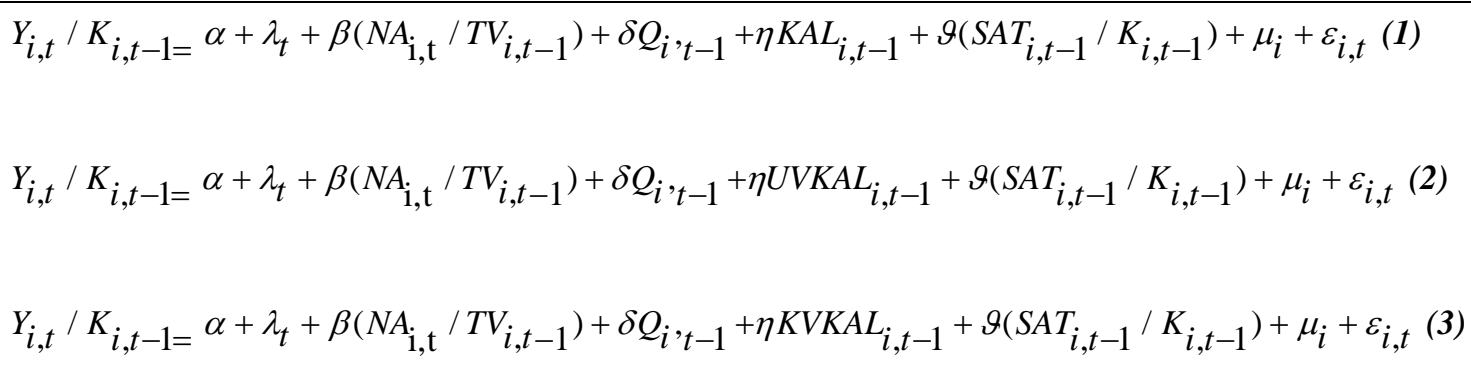 } \\
\hline & \multicolumn{2}{|l|}{ Model 1} & \multicolumn{2}{|l|}{ Model 2} & \multicolumn{2}{|l|}{ Model 3} \\
\hline & Katsay1 & P-Değeri & Katsayı & P-Değeri & Katsay 1 & P-Değeri \\
\hline Sabit & 0.126 & $0.001^{* * *}$ & 0.042 & 0.144 & 0.074 & $0.020^{* *}$ \\
\hline$N A_{\mathrm{i}, \mathrm{t}} / T V_{i, t-1}$ & 0.226 & $0.003^{* * *}$ & 0.024 & $0.002^{* * *}$ & 0.226 & $0.003^{* * *}$ \\
\hline$Q_{i},_{t-1}$ & 0.008 & 0.397 & 0.008 & 0.401 & 0.008 & 0.415 \\
\hline$K A L_{i, t-1}$ & -0.244 & $0.000 * * *$ & & & & \\
\hline$U V K A L_{i, t-1}$ & & & -0.013 & 0.161 & & \\
\hline KVKAL i, $t-1$ & & & & & -0.1727 & $0.008^{* * *}$ \\
\hline$S A T_{i, t-1} / K_{i, t-1}$ & 0.032 & $0.000^{* * *}$ & 0.031 & $0.000^{* * *}$ & 0.032 & $0.000^{* * *}$ \\
\hline$\lambda 2006$ & 0.007 & 0.799 & 0.008 & 0.767 & 0.006 & 0.837 \\
\hline$\lambda 2007$ & 0.136 & 0.620 & 0.010 & 0.713 & 0.009 & 0.740 \\
\hline$\lambda 2008$ & 0.0338 & 0.218 & 0.031 & 0.268 & 0.031 & 0.255 \\
\hline$\lambda 2009$ & -0.035 & 0.206 & -0.053 & $0.051^{* *}$ & -0.043 & 0.118 \\
\hline$\lambda 2010$ & -0.019 & 0.476 & -0.030 & 0.266 & -0.025 & 0.355 \\
\hline$\lambda 2011$ & 0.046 & 0.096* & 0.033 & 0.246 & 0.041 & 0.139 \\
\hline$\lambda 2012$ & -0.004 & 0.890 & -0.019 & 0.475 & -0.011 & 0.683 \\
\hline$\lambda 2013$ & 0.026 & 0.423 & 0.008 & 0.818 & 0.015 & 0.642 \\
\hline
\end{tabular}




\begin{tabular}{|l|l|l|l|}
\hline F-Değeri & 11.80 & 10.67 & 11.15 \\
\hline $\mathrm{N}$ & \multicolumn{1}{|c|}{1076} & 1076 & 1076 \\
\hline
\end{tabular}

***\%1 düzeyinde anlamlı, **\%5 düzeyinde anlamlı, *\%10 düzeyinde anlamlı

Tablo 4: Panel Veri Analizi Sonuçları- Yüksek ve Düşük Büyüme Fırsatları

\begin{tabular}{|c|c|c|c|c|c|c|}
\hline \multicolumn{7}{|c|}{ 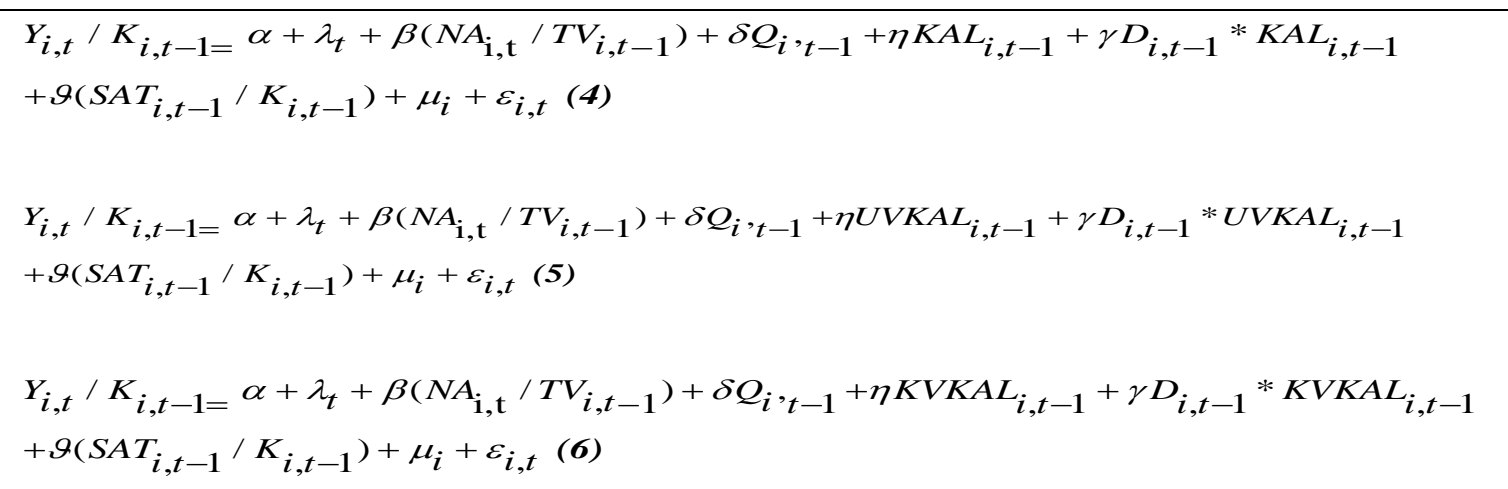 } \\
\hline & \multicolumn{2}{|l|}{ Model 4} & \multicolumn{2}{|l|}{ Model 5} & \multicolumn{2}{|l|}{ Model 6} \\
\hline & Katsayı & P-Değeri & Katsay1 & P-Değeri & Katsayı & P-Değeri \\
\hline Sabit & 0.146 & $0.000^{* * *}$ & 0.046 & 0.114 & 0.092 & $0.006^{* * *}$ \\
\hline$N A_{i, t} / T V_{i, t-1}$ & 0.215 & $0.004^{* * *}$ & 0.233 & $0.002^{* * *}$ & 0.215 & $0.005^{* * *}$ \\
\hline$Q_{i}, t-1$ & 0.006 & 0.549 & 0.007 & 0.462 & 0.006 & 0.542 \\
\hline$K A L_{i, t-1}$ & -0.329 & $0.000^{* * *}$ & & & & \\
\hline$U V K A L_{i, t-1}$ & & & -0.208 & 0.125 & & \\
\hline$K V K A L i, t-1$ & & & & & -0.273 & $0.001^{* * *}$ \\
\hline$S A T_{i, t-1} / K_{i, t-1}$ & 0.313 & $0.000^{* * *}$ & $0.031^{* *}$ & $0.000^{* * *}$ & 0.320 & $0.000^{* * *}$ \\
\hline$D_{i, t-1} * K A L_{i, t-1}$ & 0.0812 & $0.051^{* *}$ & & & & \\
\hline$D_{i, t-1} * U V K A L_{i, t-1}$ & & & 0.097 & 0.423 & & \\
\hline$D_{i, t-1} * K V K A L_{i, t-1}$ & & & & & 0.101 & $0.061^{*}$ \\
\hline$\lambda 2006$ & 0.002 & 0.945 & 0.007 & 0.804 & 0.001 & 0.983 \\
\hline$\lambda 2007$ & 0.011 & 0.677 & 0.010 & 0.723 & 0.006 & 0.817 \\
\hline$\lambda 2008$ & 0.028 & 0.310 & 0.029 & 0.295 & 0.026 & 0.356 \\
\hline$\lambda 2009$ & -0.026 & 0.358 & -0.051 & $0.063^{*}$ & -0.035 & 0.214 \\
\hline$\lambda 2010$ & -0.021 & 0.429 & -0.031 & 0.257 & -0.028 & 0.310 \\
\hline$\lambda 2011$ & 0.041 & 0.138 & 0.031 & 0.268 & 0.037 & 0.195 \\
\hline$\lambda 2012$ & -0.005 & 0.837 & -0.020 & 0.463 & -0.014 & 0.623 \\
\hline
\end{tabular}




\begin{tabular}{|l|l|l|l|l|l|l|}
\hline$\lambda 2013$ & 0.022 & 0.507 & 0.005 & 0.868 & 0.011 & 0.739 \\
\hline F-Değeri & 11.22 & 9.90 & & 10.59 & \\
\hline $\mathrm{N}$ & 1076 & 1076 & 1076 & \\
\hline
\end{tabular}

***\%1 düzeyinde anlamlı, ${ }^{* *} \% 5$ düzeyinde anlamlı, $* 10$ düzeyinde anlamlı

Yüksek ve düşük kaldıraç değerine sahip firmalar için kaldıraç, büyüme firsatları ve yatırım ilişkisi Tablo 5'de verilmiştir. Veri ve Yöntem bölümünde ifade edildiği gibi $D_{k d u ̈ s u ̈ k, t-1}$ kukla değişkeni, toplam yabancı kaynaklar kullanılarak hesaplanan kaldıraç oranı 1. katrile $(0.2732)^{4}$ eşit ya da küçük ise 1 değerini alırken, $D_{\text {kyüksek,t-1 }}$ kukla değişkeni, söz konusu kaldıraç oranı 3. kartile (0.6059) eşit ya da yüksek ise 1 değerini almaktadır. $D_{\text {kdüsü }, t-1} * Q_{i, t-1}$ değişkeni ise $D_{\text {kdüșï }, t-1}$ kukla değiş̧keni ve bir önceki dönemin Tobin Q oranı çarpımından oluşan bir etkileşim terimidir. Aynı şekilde, $D_{k y u ̈ k s e k, t-1} * Q_{i, t-1}$ değişkeni $D_{k y u ̈ k s e k, t-1}$ ve bir önceki dönemin Tobin Q oranı çarpımından oluşan bir etkileşim terimidir.

Benzer şekilde uzun vadeli borçlanma oranı ile oluşturulan Model (8)'de $D_{u v k d u ̈ s u ̈ k, t-1}$, uzun vadeli yabancı kaynaklar kullanılarak hesaplanan kaldıraç oranı, 1. katrile (0.0379) eşit ya da küçük ise 1 değerini alırken, $D_{u v k y u ̈ k s e k, t-1}$, söz konusu kaldıraç oranı 3. katrile (0.1716) eşit ya da yüksek ise 1 değerini almaktadır.

Kısa vadeli borçlanma oranlarının kullanıldığ 1 Model 9'da $D_{k v k d u ̈ s u ̈ k, t-1}$, kısa vadeli yabancı kaynaklar kullanılarak hesaplanan kaldıraç oranı 1. katrile (0.1719) eşit ya da küçük ise 1 değerini alırken, $D_{\text {kvkyüksek,t-1}}$ değişkeni ise söz konusu kaldıraç oranı 3. katrile (0.4459) eşit ya da yüksek ise 1 değerini almaktadır.

Model (7)’nin analiz sonucuna göre etkileşim terimlerine ilişkin katsayılar negatif olmasına rağmen ilişki istatistiki açıdan anlamlı değildir. Oldukça yüksek/düşük düzeyde kaldıraca sahip olan firmalarda büyüme fırsatlarının yatırımlar üzerine etkisi istatistiki açıdan anlamlı bulunmamıştır. Uzun vadeli borçların kullanıldığı Model (8)'de ve kısa vadeli borçların kullanıldığı oluşturulan Model (9)'da ise düşük düzeyde kaldıraç ve büyüme fırsatlarının çarpımından oluşan etkileşim terimlerinin katsayıları negatiftir ve sırası ile \%5 ve \%10 düzeylerinde anlamlıdır. Düşük düzeyde uzun vadeli borç düzeyine sahip firmalarda büyüme firsatlarının katsayısı -0.004 (0.023-0.027) iken, düşük düzeyde kısa vadeli borca sahip firmalarda katsayı 0.001 (0.027-0.026) olarak belirlenmiştir. Her üç modelde de satışlar, nakit akımları ve yatırımlar ilişkisi pozitiftir. Model (8) ve Model (9)' da Tobin Q değişkeni de $\% 10$ düzeyinde anlamlı ve pozitiftir.

${ }^{4}$ Bkz. Tablo 1. Özet İstatistikler 
Tablo 5: Panel Veri Analizi Sonuçları- Yüksek ve Düşük Kaldıraç Oranları

\begin{tabular}{|c|c|c|c|c|c|c|}
\hline \multicolumn{7}{|c|}{ 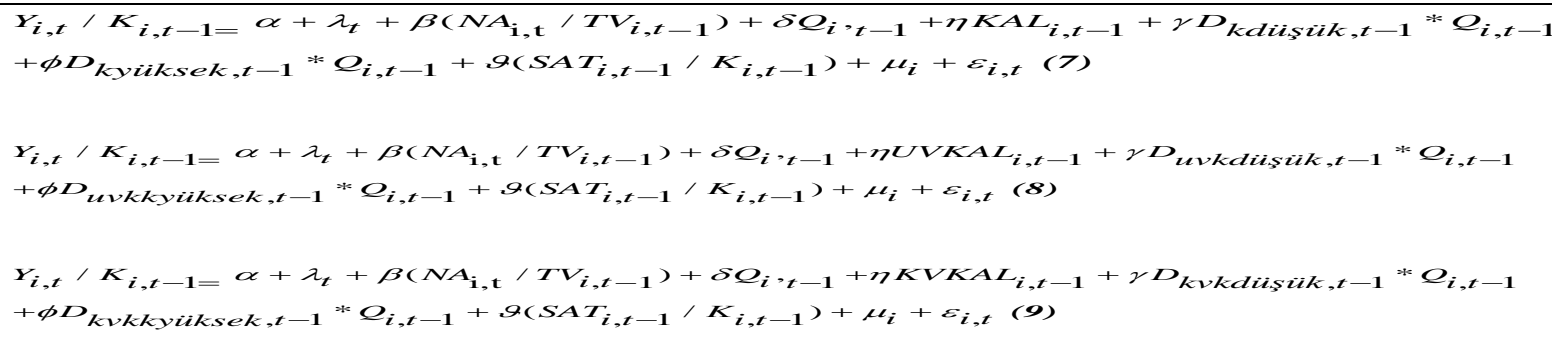 } \\
\hline & \multicolumn{2}{|l|}{ Model 7} & \multicolumn{2}{|l|}{ Model 8} & \multicolumn{2}{|l|}{ Model 9} \\
\hline & Katsay1 & P-Değeri & Katsayı & P-Değeri & Katsayı & P-Değeri \\
\hline Sabit & 0.1322 & $0.001 * * *$ & 0.034 & 0.253 & 0.076 & $0.026^{* *}$ \\
\hline$N A_{i, \mathrm{t}} / T V_{i, t-1}$ & 0.230 & $0.002 * * *$ & 0.234 & $0.002^{* * *}$ & 0.231 & $0.002^{* * *}$ \\
\hline$Q_{i}{ }_{t-1}$ & 0.017 & 0.158 & 0.023 & $0.058^{*}$ & 0.027 & $0.070^{*}$ \\
\hline$K A L_{i, t-1}$ & -0.272 & $0.001^{* * *}$ & & & & \\
\hline$U V K A L_{i, t-1}$ & & & -0.124 & 0.222 & & \\
\hline$K V K A L i, t-1$ & & & & & -0.239 & $0.003^{* * *}$ \\
\hline$S A T_{i, t-1} / K_{i, t-1}$ & 0.032 & $0.000 * * *$ & 0.031 & $0.000^{* * *}$ & 0.032 & $0.000 * *$ \\
\hline$D_{k d \ddot{s} u ̈ u k, t-1} * Q_{i, t-1}$ & -0.017 & 0.200 & & & & \\
\hline$D_{\text {kyüksek,t-1}} * Q_{i, t-1}$ & 0.002 & 0.906 & & & & \\
\hline$D_{u v k d u ̈ s u ̈ u k, t-1} * Q_{i, t-1}$ & & & -0.027 & $0.020^{* *}$ & & \\
\hline$D_{\text {uvkyüksek }, t-1}$ & & & -0.012 & \begin{tabular}{|l|}
0.399 \\
\end{tabular} & & \\
\hline$D_{k v k d u ̈ s ̧ u ̈ k, t-1}$ & & & & & -0.026 & $0.055^{*}$ \\
\hline$D_{k v k y u ̈ k s e k, t-1}$ & & & & & 0.013 & 0.447 \\
\hline$\lambda 2006$ & 0.007 & 0.806 & 0.006 & 0.818 & 0.004 & 0.894 \\
\hline$\lambda 2007$ & 0.014 & 0.625 & 0.011 & 0.690 & 0.008 & 0.763 \\
\hline$\lambda 2008$ & 0.034 & 0.217 & 0.032 & 0.238 & 0.031 & 0.254 \\
\hline$\lambda 2009$ & -0.033 & 0.235 & -0.050 & 0.069* & -0.04 & 0.175 \\
\hline$\lambda 2010$ & -0.019 & 0.487 & -0.029 & 0.292 & -0.025 & 0.356 \\
\hline$\lambda 2011$ & 0.046 & 0.106 & 0.034 & 0.215 & 0.038 & 0.179 \\
\hline$\lambda 2012$ & -0.003 & 0.911 & -0.017 & 0.552 & -0.013 & 0.651 \\
\hline$\lambda 2013$ & 0.027 & 0.418 & 0.006 & 0.847 & 0.013 & 0.685 \\
\hline F-Değeri & 10.23 & & 9.58 & & 9.91 & \\
\hline $\mathrm{N}$ & 1076 & & 1076 & & 1076 & \\
\hline
\end{tabular}


***\%1 düzeyinde anlamlı,** \%5 düzeyinde anlamlı, *\%10 düzeyinde anlamlı

Kaldıraç ve yatırımlar arasındaki ilişkilerin analizinde değinilen bir konu da endojenlik konusudur (Lang, vd., 1996: 3- 4, Aivazian, vd., 2005: 286- 287). Kaldıraç oranlarının yatırımları etkilemesi gibi, gelecekteki yatırımların tahmin edilip kaldıraç oranlarının bu beklenti dahilinde ayarlanabilmesi ihtimali de bulunabilmektedir. Sorunun panel veri analizi kapsamında çözümünde sorun araç değişken (instrumental variable) yardımıyla çözülmektedir. Kullanılacak araç değişkenin iki koşulu sağlaması gerekmektedir ki bunlardan birincisi aracın dışsal olması, ikincisi ise aracın uygun olmasıdır (Wooldridge, 2013: 508). Dolayısıyla, araç değişkenin seçiminde, kaldıraç oranları ile korelasyonu yüksek ancak yatırımlarla korelasyonu düşük bir araç değişken kullanmaya özen gösterilmelidir. Aivaizan vd. (2005) araç değişken olarak maddi duran varlıkların toplam varlıklara oranını kullanmışlardır. Bu çalışmada da aynı değişken araç değişken olarak kullanılmak istenmiş ancak söz konusu değişkenin zayıf bir araç olduğu saptanmıştır. ${ }^{5}$ Zayıf bir araç kullanılarak alınan sonuçlar ise yanıltıcı olabilmektedir. Kaldıraç oranı ile yüksek korelasyona ve yatırımlarla düşük korelasyona sahip başka bir araç değişken ise bulunamamıştır.

Çalışma sonuçları diğer çalışmalarla karşılaştırıldığında, yatırımlar ve kaldıraç arasında bulunan negatif ilişski Lang vd. (1996), Aivazian vd. (2005), Bao (2010), Karacaer vd. (2009), Ma'in ve İsmail (2010)'in çalışma sonuçları ile uyumludur. Borcun aşırı yatırım problemini azalttığı sonucu ise Lang vd. (1996), Aivazian vd. (2005), Ma'in ve İsmail (2010) ve $\mathrm{Wu}$ (2013)'ün sonuçlarını desteklemektedir. Ancak yüksek ve düşük düzeyde kaldıraç oranlarına sahip firmalarda büyüme fırsatları ve yatırımlar arasındaki ilişki Bao (2010)'un bulduğu sonucun aksine düşük kaldıraç oranlarına sahip firmalarda negatif yönlüdür.

\section{SONUÇ}

$\mathrm{Bu}$ çalışmada yatırımların, kaldıraç oranları ve büyüme firsatlarından ne şekilde etkilendiği analiz edilmiştir. Çalışmada yatırımların çalışmada kullanılan tüm kaldıraç oranlarından negatif yönde etkilendiği, satışlar ve nakit akımlarının ise yatırımlar üzerinde pozitif etkiye sahip olduğu sonucuna varılmıştır. Çalışma sonucunda, düşük büyüme fırsatlarına sahip firmalarda, kaldıracın yatırımlar üzerindeki etkisinin yüksek büyüme firsatlarına sahip firmalardakine göre daha güçlü olduğu ortaya konulmuştur. $\mathrm{Bu}$ sonuç borcun firma yönetimini disipline ettiği ve aşırı yatırımı azalttığı yönündeki temsilcilik teorisi

\footnotetext{
${ }^{5}$ Araç değişkenin zayıf olduğuna ilişkin sonuçlar ve araç değişsen kullanılarak yapılan analiz istenildiği takdirde temin edilecektir.
} 
ile uyumludur. Yüksek büyüme fırsatlarına sahip firmalarda da kaldıraç ve yatırımlar arasındaki ilişki negatif olsa da, yüksek düzeyde kaldıraca sahip firmalar için büyüme fırsatları ve yatırım ilişkisi istatistiki açıdan anlamlı değildir. Çok düşük düzeylerde uzun vadeli borçlanan firmalarda büyüme firsatları yatırımları negatif yönde etkilemektedir. Çok düşük düzeyde kısa vadeli borcu olan firmalarda ise büyüme firsatları yatırımları pozitif yönde etkilemektedir. Bu nedenle çalışmada borcun Myer's (1977)'ın ifade ettiği şekilde eksik yatırım problemini teşvik edip etmediği konusunda bir sonuca varılamamıştır.

\section{KAYNAKLAR}

Ahn, S. Denis, D.J.,Denis, D.K. (2004), Leverage and Investment in Diversified Firms. Journal of Financial Economics, 79 (2), 317-337.

Aivazian, A. V., Ge, Y., Qiu, J. (2005). The Impact of Leverage on Firm Investment, Canadian Evidence, Journal of Corporate Finance, 11, 277- 291.

Alonso, P., Lopez Iturriaga, F.J., Rodriguez Sanz, J. A. (2005), Financial Decisions and Growth Opportunities: A Spanish Firms Panel Data Analysis, Applied Financial Economics, 15, 391-407

Baltagi, B. H. (1995) Econometric Analysis of Panel Data, West Sussex: Willey and Sons

Bao, H. (2010). A Study on Leverage and Firm Investment:Chinese Evidence. (Yüksek Lisans Tezi), KTH Royal Institute of Technology, https://www.kth.se/polopoly_fs/1.16909!/Menu

/general/column-content/attachment/Huijie\%20Bao.pdf adresinden alındı.

Chung, K. H.,Pruitt, S. W. (1994). A Simple Approximation of Tobin's Q, Financial Management, 23 (3), 70-74.

Dougherty, C. (2007). Introduction to Econometrics, New York: Oxford Univesity Press.

Franklin, J.S.,Muthusamy, K. (2011). Impact of Leverage on Firms Investment Decision. International Journal of Scientific\&EngineeringResearch, 2(4), 1-16.

Greene, W. H. (2003) Econometric Analysis, New York: Macmillan Publishing Company

Harvey,C.,Lins,K.V., Roper, A. (2004). TheEffect of Capital Structure When Expected Agency Costs Are Extreme, Journal of Financial Economics, 74, 3-30.

Hausman, J. A. (1978). Specification Tests in Econometrics, Econometrica, 46(6), 12511271.

Hsiao, C. (1986). Analysis of Panel Data, Cambridge: Cambridge University Press.

Hsiao, C., (2005). Why Panel Data? ( IEPR Working Papers, no.05.33)., DOI: 10.2139/ssrn.820204, http://papers.ssrn.com/sol3/papers.cfm?abstract_id=820204 adresinden alınd1.

Jensen, M.C. (1986). Agency Cost of Free Cash Flow, Corporate Finance and Takeovers. 
American Economic Review, 76, 323-329.

Karacaer, S., Aygün, M., İç, S. Firma Yatırımları Üzerinde Kaldıracın Etkisi: Türk Sermaye Piyasası Üzerinde Bir İnceleme, Finans, Politik ve Ekonomik Yorumlar, 46 (583), 3542.

Lang, L.E.,Ofek, E., Stulz, R. (1996). Leverage, Investment and FirmGrowth. Journal of Financial Economics, 40 (1), 3-29.

Ma'in, M. İsmail, A.G.(2011). Impact of Debt Ratio on Firm Investment: Evidence from Malazian listed firms. International Proceedings of Economics Development and Research, 3, 134-138.

McConnell, J. Servaes, H. (1995). Equity Ownership and the Two Faces of Debt, Journal of Financial Economics, 39, 131-157.

Modigliani, F., MILLER, M. H. (1958). The Cost of Capital, Corporation Finance and the Theory of Investment.American EconomicReview, 48, 261-297.

Myers, S.C. (1977). Determinants of Corporate Borrowing. Journal of Financial Economics, 5, 147-175. Journal of Financial Economics, 39, 131-157.

Stulz, R.M. (1990). Managerial Discretion and Optimal Financing Policies. Journal of Financial Economics, 26, 3-27.

Umutlu, M. (2010) Firm Leverage and Investment Decisions in an Emerging Market, Ouality \&Quantity, 44 (5), 1005-1013.

Wooldridge, J, M. (2013). Ekonometriye Giriş Modern Yaklaşım, Çeviri Editörü: Ebru Çağlayan, Nobel Yayıncılık, 507-509.

Wu, Y. (2013). Leverage and Firm growth: European Evidences. (Yüksek Lisans Tezi ), AaltoUniversity School of Business, http://epub.lib.aalto.fi/en/ethesis/pdf/13136/

hse_ethesis_13136.pdf adresinden alındı. 